Original Article

\title{
Effects of a dynamic chair on pelvic mobility, fatigue, and work efficiency during work performed while sitting: a comparison of dynamic sitting and static sitting
}

\author{
Hironori Tanoue ${ }^{1,2)^{*}}$, Toshitaka Mitsuhashi ${ }^{3)}$, Shunj $\mathrm{Sako}^{2,4)}$, Ryokichi Gotol), \\ TOMOHIRO NAKAI ${ }^{1)}$, RYOICHI INABA ${ }^{2)}$ \\ 1) Department of Rehabilitation, Aichi Koseiren Asuke Hospital: 20 Nakata, Yagami-cho, Toyota-shi, \\ Aichi 444-2351, Japan \\ 2) Department of Occupational Health, Graduate School of Medicine, Gifu University, Japan \\ 3) Nishimikawa Home Nursing Station, Japan \\ 4) Department of Physical Therapy, Nagoya Isen School Corporation Vocational College, Japan
}

\begin{abstract}
Purpose] Working while sitting for long periods can cause lumbar pain, fatigue, and reduced work efficiency. How a dynamic chair with a seat that moves three-dimensionally affects pelvic mobility before and after work, work efficiency, and post-work fatigue were examined. [Subjects and Methods] Subjects were 17 healthy adults (10 males, 7 females, mean age $21.8 \pm 2.7$ years). Subjects performed a 30 -min Kraepelin test under two conditions: sitting in a standard office chair and sitting in a dynamic sitting balance chair. Root mean square (RMS) values of pelvic movement measured by a triaxial accelerometer during 30 minutes of work, finger-floor distance before and after work, lumbar fatigue, and pelvic movement RMS values during finger-floor distance measurement were used as outcome measures. [Results] Pelvic movement RMS values collected every 5 minutes during 30 minutes of work were significantly higher while sitting in the dynamic balance chair. Changes in pelvic movement RMS values during finger-floor distance measurement after work and amount of work performed during 30 minutes were significantly higher and lumbar fatigue was significantly lower for the dynamic balance chair. [Conclusion] Dynamic sitting maintained or increased pelvic flexibility. The dynamic balance chair may effectively help workers work continuously in seated postures with little fatigue.

Key words: Pelvis, Sitting, Ergonomics
\end{abstract}

(This article was submitted Jan. 21, 2016, and was accepted Feb. 22, 2016)

\section{INTRODUCTION}

Many office workers perform work while sitting in chairs ${ }^{1}$. A previous study reported that workers in sedentary jobs spent an average of $10 \mathrm{~h}$ in a seated posture during a 24-h period ${ }^{2}$. Prolonged sitting at sub-optimal workstations is associated with musculoskeletal dysfunction ${ }^{3-5}$. While seated postures are less physically stressful overall than are standing postures, they place significant mechanical stress on the lumbar vertebrae. Thus, maintaining a static seated posture is a risk factor for low back pain ${ }^{6,7)}$. In 2013, the Japanese government published guidelines for preventing low back pain at work. These recommend placing the lower back deep into the chair during work and supporting the trunk with a backrest ${ }^{8,9)}$. The purpose of a backrest in an office chair is to support lumbar lordosis and to attenuate disc pressure that occurs as a result of gravity ${ }^{10-13)}$. Proper posture is a state of musculoskeletal balance that minimizes the stresses and strains acting on the body ${ }^{14,15)}$. However,

*Corresponding author. Hironori Tanoue (E-mail: tanohiro2@gmail.com)

(C2016 The Society of Physical Therapy Science. Published by IPEC Inc.

This is an open-access article distributed under the terms of the Creative Commons Attribution Non-Commercial No Derivatives (by-nc-nd) License $<$ http://creativecommons.org/licenses/by-nc-nd/4.0/>. 
maintaining the ideal seated posture during prolonged sitting is difficult ${ }^{16,17)}$ and incorporating movement into sitting is one way of reducing physical stress ${ }^{18,19)}$.

Adjustable sit-stand workstations have reportedly helped to reduce neck and low back pain and improved subjective feelings of health by reducing the amount of time spent sitting during work ${ }^{20,21)}$. However, Chester et al. reported that sit-stand workstations are associated with greater swelling of the feet than the seated position ${ }^{22}$. Thus, the validity of the sit-stand workstation is not clear ${ }^{18,23,24)}$. Researchers have also examined the effectiveness of sitting in dynamic chairs that have moveable seats. Dynamically changing the positions of the lumbar vertebrae and pelvis during sitting has been found to help reduce posture-related pain ${ }^{6,25}$. O'Keeffe et al. compared the effects of a dynamic chair, a forward-inclined chair, and a standard office chair designed for comfort, and reported that the dynamic chair was associated with less discomfort with respect to the back portion of the chair ${ }^{26)}$. Annetts et al. measured the angles of posterior pelvic inclination, lumbar lordosis, and neck and head inclinations of the subjects seated in four different chairs. In their comparison of dynamic and static chairs, none created the ideal posture for every part studied, and they recommended selecting a chair that meets an individual's needs ${ }^{27}$. Van Dieën et al. ${ }^{28)}$ examined erector spinae muscle activity during desk work using office chairs with different levels of seat and backrest mobility. They did not observe different levels of muscle activity in the sagittal plane or body movements among the different chairs examined.

As noted above, the validity of previous studies comparing dynamic and static sitting is not clear ${ }^{19,29)}$. A previous study of dynamic sitting reported using the chair that moved in a longitudinal direction and considered movement only in two dimensions. In the present study, three-dimensional movement in a movable dynamic chair was measured using triaxial accelerometers to determine the effects of a dynamic chair on pelvic mobility before and after work, work efficiency, and post-work fatigue.

\section{SUBJECTS AND METHODS}

The subjects were 17 students enrolled from Gifu Junior College of Health and Science (10 males, 7 females, mean age $21.8 \pm 2.7$ years). The inclusion criterion was good general health (that is, individuals who were not currently being treated for a disease and who had no physical pain or unidentified complaints). The exclusion criteria were marked deformities of the neck (cervical vertebrae), trunk (thoracic/lumbar vertebrae), or pelvis and a history of neck or low back pain.

Work was performed while seated under two conditions: in a standard office chair (SOC) (condition 1) and in a dynamic sitting balance chair (DSBC) (Finggal Link, Tokyo, Japan) (condition 2).

For condition 1, an office chair (ITOKI JOIFA 602, Itoki Corp., Osaka, Japan) with adjustable seat height, a backrest fixed in a $70^{\circ}$ retroflexed position, and no armrests was used. Subjects worked in a fixed posture with their lower backs deep in the chair, their soles in full contact with the ground, and their backs completely against the backrest. For condition 2, we used a DSBC with a seat that could tilt freely $15^{\circ}$ anteroposteriorly and laterally in line with movements of the center of gravity. The DSBC had no armrests and its height was adjustable.

The Uchida-Kraepelin test (UK-t) was used for the work task. In the UK-t, a subject performs single-digit sums, changing lines every minute. The task is performed in two 15 -minute sessions with a 5-minute rest in between. The test is used to examine work efficiency, as well as behavioral characteristics. During the work sequence, subjects used a UK-t sheet and followed spoken instructions from a CD. Each subject performed the task under both conditions, with at least 1 day in between. The order of the conditions was randomized.

Pelvic movements were monitored during the 30 minutes of work using a small, 8-channel wireless motion recorder (Micro Stone, MVP-RF8-BC). The sensor weighs about $60 \mathrm{~g}$ and was taped to the posterior surface of the sacrum and held in place with a belt. Data were transmitted wirelessly to a personal computer (TOSHIBA DYNABOOK, Windows XP) with a Bluetooth-USB adaptor (Parani-UD100). The sampling frequency was $10 \mathrm{~Hz}$. The root mean square [RMS] values of pelvic motion were calculated from the acceleration values measured every 5 minutes.

For the measurement of the finger-floor distance (FFD), subjects stood on a platform $20 \mathrm{~cm} \mathrm{high,} \mathrm{flexed} \mathrm{the} \mathrm{trunk} \mathrm{and}$ dropped both arms to the floor. This distance from the tip of the third finger to the floor when the trunk was at maximum flexion was measured as the FFD. An accelerometer was attached to the posterior surface of the sacrum to record the motions when moving from the standing position to maximum trunk flexion and back to standing. The procedure followed that of Solomonow et $\mathrm{al}^{30}$. The subjects started by standing at rest for 3 seconds with their feet shoulder-width apart. Then taking 4 seconds they bent forward dropping both arms and keeping the knees extended. After staying at maximum flexion for 4 seconds, they returned to standing, again taking 4 seconds to do so. RMS values were calculated from the acceleration values taken from the start of the forward bend until the subject returned to the standing position. The sampling frequency was $1,000 \mathrm{~Hz}$.

Post-work fatigue in the lumbar area was assessed using the visual analog scale (VAS). A VAS chart based on the Guideline for Clinical Evaluation of Anti-Fatigue that was prepared by the Japanese Society of Fatigue Science to assess subjective levels of mental and physical fatigue was used ${ }^{31)}$.

The number of calculations performed during the UK-t was determined for each 5-minute interval during the 30 minutes of work.

The subjects received a full written explanation of the study's intent, its content, protection of personal information, and 
Table 1. Temporal changes in pelvic motion root mean square values over the 30 minutes of work performed while sitting

\begin{tabular}{|c|c|c|c|c|c|c|c|c|}
\hline \multirow[b]{2}{*}{$\begin{array}{l}\text { Time } \\
\text { (minutes) }\end{array}$} & \multicolumn{4}{|c|}{ Condition 1} & \multicolumn{4}{|c|}{ Condition 2} \\
\hline & $\begin{array}{c}\text { Lateral } \\
\text { component }\end{array}$ & $\begin{array}{c}\text { Vertical } \\
\text { component }\end{array}$ & $\begin{array}{l}\text { Anteroposterior } \\
\text { component }\end{array}$ & $\begin{array}{c}\text { Total } \\
\text { component }\end{array}$ & $\begin{array}{c}\text { Lateral } \\
\text { component }\end{array}$ & $\begin{array}{c}\text { Vertical } \\
\text { component }\end{array}$ & $\begin{array}{l}\text { Anteroposterior } \\
\text { component }\end{array}$ & $\begin{array}{c}\text { Total } \\
\text { component }\end{array}$ \\
\hline $0-5$ & $0.01 \pm 0.03$ & $0.02 \pm 0.03$ & $0.03 \pm 0.08$ & $0.05 \pm 0.01$ & $0.2 \pm 0.3$ & $0.006 \pm 0.01$ & $0.2 \pm 0.3$ & $0.4 \pm 0.4$ \\
\hline $5-10$ & $0.02 \pm 0.06$ & $0.04 \pm 0.06$ & $0.1 \pm 0.3$ & $0.2 \pm 0.3$ & $0.2 \pm 0.2$ & $0.02 \pm 0.04$ & $0.6 \pm 0.9$ & $0.9 \pm 1.0$ \\
\hline $10-15$ & $0.03 \pm 0.05$ & $0.07 \pm 0.09$ & $0.2 \pm 0.5$ & $0.3 \pm 0.5$ & $0.3 \pm 0.3$ & $0.03 \pm 0.06$ & $0.8 \pm 1.2$ & $1.2 \pm 1.3$ \\
\hline $15-20$ & $0.07 \pm 0.1$ & $0.05 \pm 0.08$ & $0.5 \pm 0.7$ & $0.8 \pm 0.9$ & $0.4 \pm 0.4$ & $0.2 \pm 0.3$ & $1.2 \pm 1.8$ & $1.7 \pm 2.2$ \\
\hline $20-25$ & $0.1 \pm 0.1$ & $0.06 \pm 0.1$ & $0.5 \pm 0.8$ & $0.8 \pm 0.9$ & $0.6 \pm 0.6$ & $0.2 \pm 0.3$ & $1.3 \pm 2.2$ & $2.0 \pm 2.6$ \\
\hline $25-30$ & $0.1 \pm 0.2$ & $0.07 \pm 0.1$ & $0.6 \pm 0.9$ & $0.8 \pm 1.0$ & $0.6 \pm 0.6$ & $0.2 \pm 0.3$ & $1.2 \pm 1.9$ & $1.9 \pm 2.2$ \\
\hline
\end{tabular}

Values are mean \pm standard deviation. Condition 1: a standard office chair was used for the work task. Condition 2: a dynamic sitting balance chair was used for the work task.

Lateral component: Condition: $F=38.983, p<0.01$; Time: $F=2.768, p<0.05$; Condition $\times$ Time: $F=1.129, p=0.346$

Vertical component: Condition: $F=5.087, p<0.05$; Time: $F=3.447, p<0.01$; Condition $\times$ Time: $F=2.196, p=0.057$

Anteroposterior component: Condition: $F=17.128, p<0.01$; Time: $F=3.522, p<0.01$; Condition $\times$ Time: $F=0.387, p=0.858$

Total component: Condition: $\mathrm{F}=27.626, \mathrm{p}<0.01$; Time: $\mathrm{F}=5.652, \mathrm{p}<0.01$; Condition $\times$ Time: $\mathrm{F}=0.501, \mathrm{p}=0.775$

Table 2. Changes in post-work fatigue and finger-floor distance and the pelvic motion root mean square between pre- and post-work

\begin{tabular}{llcc}
\hline & & Condition 1 & Condition 2 \\
\hline VAS $(\mathrm{cm})^{*}$ & & $2.6 \pm 1.6$ & $1.9 \pm 1.6$ \\
FFD $(\mathrm{cm})^{*}$ & Amount of change & $-2.5 \pm 6.8$ & $2.4 \pm 3.6$ \\
RMS & Pre-work & $33.9 \pm 25.7$ & $32.1 \pm 22.5$ \\
& Post-work & $31.4 \pm 18.5$ & $37.3 \pm 20.8$ \\
& Amount of change* & $-2.5 \pm 16.2$ & $5.2 \pm 11.4$ \\
\hline
\end{tabular}

Values are mean \pm standard deviation. *differences are significant $(\mathrm{p}<0.05)$. Condition 1 : a standard office chair was used for the work task. Condition 2: a dynamic sitting balance chair was used for the work task.

VAS: visual analog scale, FFD: finger-floor distance, RMS: root mean square

potential risks. The study was conducted only after obtaining the subjects' consent in writing. The study was approved by the Ethics Committee of Gifu Junior College of Health Science.

Pelvic RMS values during work and the amount of work performed during the UK-t were compared between the conditions using a two-way factorial analysis of variance. Post-work fatigue and pelvic motion RMS and FFD values before and after work were examined using the paired t-test. SPSS 11.0 J for Windows was used for the statistical analysis, where values with a significance of $\mathrm{p}<0.05$ were accepted.

\section{RESULTS}

The distribution analysis comparing the two conditions revealed that the pelvic motion RMS values during work under condition 2 were significantly higher than under condition 1 for the overall motion and each of its triaxial components in each 5 -minute interval during the 30-minute UK-t $(\mathrm{p}<0.01)$. The analysis of variance showed significant differences over time for the overall motion and each of its triaxial components $(\mathrm{p}<0.01)$ (Table 1$)$.

The difference in FFD between before and after work was significantly greater after work under condition 2 than after work under condition $1(\mathrm{p}<0.05)$ (Table 2).

The change in RMS values from standing to maximum trunk flexion and back to standing between before and after work was significantly greater after work under condition 2 than under condition $1(\mathrm{p}<0.05)$ (Table 2$)$.

Significantly lower VAS values were observed after work under condition 2 than under condition $1(p<0.05)($ Table 2$)$.

The amount of work performed over 30 minutes in the UK-t while sitting was significantly greater after work under condition 2 than under condition $1(\mathrm{p}<0.05)$. The analysis of variance of work performance over time showed a significant difference $(\mathrm{p}<0.01)$ (Table 3$)$.

\section{DISCUSSION}

In the present study, the effects of a dynamic chair on fatigue before and after work, pelvic mobility, and work efficiency were investigated. The pelvic motion RMS values of overall motion and its lateral, vertical, and anteroposterior components 
Table 3. Amount of work performed in 5-minute intervals during the 30 minutes of work performed while sitting

\begin{tabular}{lcccccc}
\hline Time (minutes) & $0-5$ & $5-10$ & $10-15$ & $15-20$ & $20-25$ & $25-30$ \\
\hline Condition 1 & $255.3 \pm 81.6$ & $238.5 \pm 78.9$ & $241.8 \pm 81.5$ & $272.8 \pm 81.4$ & $263.6 \pm 80.3$ & $261.9 \pm 82.7$ \\
Condition 2 & $259.2 \pm 76.1$ & $251.5 \pm 70.1$ & $261.2 \pm 77.8$ & $285.5 \pm 80.2$ & $266.8 \pm 72.2$ & $266.8 \pm 81.5$ \\
\hline
\end{tabular}

Values are mean \pm standard deviation. Condition 1: a standard office chair was used for the work task. Condition 2: a dynamic sitting balance chair was used for the work task. Work task: The Uchida-Kraepelin test

Condition: $\mathrm{F}=4.528, \mathrm{p}<0.05$; Time: $\mathrm{F}=4.823, \mathrm{p}<0.01$; Condition $\times$ Time: $\mathrm{F}=0.357, \mathrm{p}=0.877$

at 5-minute intervals during the 30-minute UK-t were significantly higher when sitting in the DSBC than in the SOC. This indicates that more pelvic movement occurred while seated in the DSBC than while seated in the SOC with backrests. Also, pelvic movements tended to increase over time. The change in FFD between before and after work was significantly higher after work seated in the DSBC than in the SOC. Moreover, the change in the pelvic motion RMS values between before and after work while performing maximum trunk flexion and returning to standing was significantly higher after work seated in the DSBC than in the SOC. In other words, the chair that promoted pelvic movement during work helped to maintain and improve post-work physical flexibility and pelvic mobility. Pelvic movement is widely used in the treatment of low back pain $^{32-37)}$, and the effectiveness of pelvic stability exercise for patients with low back pain has become clear ${ }^{38-40)}$. Seated postures that encourage pelvic movements could help to prevent low back pain and reduce fatigue.

Post-work fatigue was significantly lower after work seated in the DSBC than in the SOC. Many previous studies have reported a proportional relationship between the amount of postural changes when sitting in office chairs for long periods and the degree of discomfort ${ }^{41-43)}$. This finding shows that people change their posture while they are seated for work to reduce discomfort, suggesting that discomfort could be reduced by making postural changes easier with more mobile seats. During work performed while sitting, people use physical movements to disperse stress when they feel fatigued, sleepy, or otherwise uncomfortable ${ }^{44)}$. Chairs with freely movable seats, rather than limiting these movements, are thought to facilitate these movements. The results of the present study, which showed that pelvic movements during work increased as time passed, support this supposition. When individuals perform work while in a sustained sitting position, a dynamic sitting posture that enables pelvic movement while sitting has been shown to reduce the burden on the body that is associated with the static sitting posture. While small physical movements are necessary to reduce posture-related pain of the pelvis and lumbar vertebrae, large changes while sitting have been shown to cause discomfort ${ }^{45)}$. The DSBC has a seat that can tilt only $15^{\circ}$ to the front, back, left, or right, so excessive movement is avoided. Significantly more work was performed during the 30-minute UK-t in the DSBC than in the SOC, suggesting that allowing the seated posture to change benefits work efficiency and that a dynamic chair may be associated with less fatigue and higher efficiency during work performed while sitting.

This study compared the effects of a SOC and a DSBC and differences in the shapes and materials of the seats may have affected the results. Future comparisons should be made under standardized conditions to address this issue. The UK-t was used as a measure of work performance, and it measures the amount of work performed over 30 minutes. Therefore, the working time was limited to 30 minutes. Although 30 minutes was sufficient to observe increases in pelvic mobility, fatigue, and work efficiency during the work performed while sitting, longer sitting durations are worthy of investigation. Additionally, this study focused on pelvic movements, but other motions, such as those of the lumbar vertebrae, head, neck, and upper limbs, should also be analyzed.

\section{REFERENCES}

1) Watanabe S, Eguchi A, Kobara K, et al.: Influence of trunk muscle co-contraction on spinal curvature during sitting for desk work. Electromyogr Clin Neurophysiol, 2007, 47: 273-278. [Medline]

2) McCrady SK, Levine JA: Sedentariness at work: how much do we really sit? Obesity (Silver Spring), 2009, 17: 2103-2105. [Medline] [CrossRef]

3) Pillastrini P, Mugnai R, Bertozzi L, et al.: Effectiveness of an ergonomic intervention on work-related posture and low back pain in video display terminal operators: a 3 year cross-over trial. Appl Ergon, 2010, 41: 436-443. [Medline] [CrossRef]

4) IJmker S, Huysmans MA, Blatter BM, et al.: Should office workers spend fewer hours at their computer? A systematic review of the literature. Occup Environ Med, 2007, 64: 211-222. [Medline] [CrossRef]

5) Robertson M, Amick BC 3rd, DeRango K, et al.: The effects of an office ergonomics training and chair intervention on worker knowledge, behavior and musculoskeletal risk. Appl Ergon, 2009, 40: 124-135. [Medline] [CrossRef]

6) Callaghan JP, McGill SM: Low back joint loading and kinematics during standing and unsupported sitting. Ergonomics, 2001, 44: 280-294. [Medline] [CrossRef]

7) Grondin DE, Triano JJ, Tran S, et al.: The effect of a lumbar support pillow on lumbar posture and comfort during a prolonged seated task. Chiropr Man Therap, 2013, 21: 21. [Medline] [CrossRef]

8) Japanese Ministry of Labour: Guidelines for Industrial Health Controls of VDT operations. Tokyo: Rodosho Kihatsu, 2002. (in Japanese).

9) Ministry of Health, Labour and Welfare: Low back pain prophylaxis guidance in the workplace. http://www.mhlw.go.jp/stf/houdou/youtsuushishin.html (In Japanese) (Accessed Nov. 3, 2015)

10) Bendix T, Poulsen V, Klausen K, et al.: What does a backrest actually do to the lumbar spine? Ergonomics, 1996, 39: 533-542. [Medline] [CrossRef] 
11) Yoo WG: Effect of a suspension seat support chair on the trunk flexion angle and gluteal pressure during computer work. J Phys Ther Sci, 2015, 27: 2989-2990. [Medline] [CrossRef]

12) Yoo WG: Effects of the ball-backrest chair combined with an accelerometer on the pain and trunk muscle endurance of a computer worker with LBP. J Phys Ther Sci, 2014, 26: 469-470. [Medline] [CrossRef]

13) Yoo WG: Comparison of sitting with and without a backrest during computer work. J Phys Ther Sci, 2012, 24: 409-410. [CrossRef]

14) Griegel-Morris P, Larson K, Mueller-Klaus K, et al.: Incidence of common postural abnormalities in the cervical, shoulder, and thoracic regions and their association with pain in two age groups of healthy subjects. Phys Ther, 1992, 72: 425-431. [Medline]

15) Waongenngarm P, Rajaratnam BS, Janwantanakul P: Perceived body discomfort and trunk muscle activity in three prolonged sitting postures. J Phys Ther Sci, 2015, 27: 2183-2187. [Medline] [CrossRef]

16) Jaraczewska E, Long C: Kinesio taping in stroke: improving functional use of the upper extremity in hemiplegia. Top Stroke Rehabil, 2006, 13: 31-42. [Medline] [CrossRef]

17) Tsuji T, Matsuyama Y, Sato K, et al.: Epidemiology of low back pain in the elderly: correlation with lumbar lordosis. J Orthop Sci, 2001, 6: 307-311. [Medline] [CrossRef]

18) Ebara T, Kubo T, Inoue T, et al.: Effects of adjustable sit-stand VDT workstations on workers' musculoskeletal discomfort, alertness and performance. Ind Health, 2008, 46: 497-505. [Medline] [CrossRef]

19) Pynt J: Rethinking design parameters in the search for optimal dynamic seating. J Bodyw Mov Ther, 2015, 19: 291-303. [Medline] [CrossRef]

20) Pronk NP, Katz AS, Lowry M, et al.: Reducing occupational sitting time and improving worker health: the Take-a-Stand Project, 2011. Prev Chronic Dis, 2012, 9: E154. [Medline] [CrossRef]

21) Dutta N, Koepp GA, Stovitz SD, et al.: Using sit-stand workstations to decrease sedentary time in office workers: a randomized crossover trial. Int J Environ Res Public Health, 2014, 11: 6653-6665. [Medline] [CrossRef]

22) Chester MR, Rys MJ, Konz SA: Leg swelling, comfort and fatigue when sitting, standing, and sit/standing. Int J Ind Ergon, 2002, 29: 289-296. [CrossRef]

23) Wilks S, Mortimer M, Nylén P: The introduction of sit-stand worktables; aspects of attitudes, compliance and satisfaction. Appl Ergon, 2006,37 : 359-365. [Medline] [CrossRef]

24) Asai $H$, Tsuchiyama $H$, Hatakeyama $T$, et al.: Relationship between the ability to perform the sit-to-stand movement and the maximum pelvic anteversion and retroversion angles in patients with stroke. J Phys Ther Sci, 2015, 27: 985-988. [Medline] [CrossRef]

25) Black KM, McClure P, Polansky M: The influence of different sitting positions on cervical and lumbar posture. Spine, 1996, 21: 65-70. [Medline] [CrossRef]

26) O'Keeffe M, Dankaerts W, O'Sullivan P, et al.: Specific flexion-related low back pain and sitting: comparison of seated discomfort on two different chairs. Ergonomics, 2013, 56: 650-658. [Medline] [CrossRef]

27) Annetts S, Coales P, Colville R, et al.: A pilot investigation into the effects of different office chairs on spinal angles. Eur Spine J, 2012, 21: S165-S170. [Medline] [CrossRef]

28) van Dieën JH, de Looze MP, Hermans V: Effects of dynamic office chairs on trunk kinematics, trunk extensor EMG and spinal shrinkage. Ergonomics, 2001, 44: 739-750. [Medline] [CrossRef]

29) O'Sullivan K, O'Sullivan P, O'Keeffe M, et al.: The effect of dynamic sitting on trunk muscle activation: a systematic review. Appl Ergon, 2013 , 44 : 628-635. [Medline] [CrossRef]

30) Solomonow M, Baratta RV, Banks A, et al.: Flexion-relaxation response to static lumbar flexion in males and females. Clin Biomech (Bristol, Avon), 2003, 18: 273-279. [Medline] [CrossRef]

31) Japanese Society of Fatigue Science (JSFS): [Visual Analogue Scale for Fatigue]. http://www.hirougakkai.com/VAS.pdf. (in Japanese) (Accessed Nov. 20, 2013)

32) Akuthota V, Nadler SF: Core strengthening. Arch Phys Med Rehabil, 2004, 85: S86-S92. [Medline] [CrossRef]

33) Barr KP, Griggs M, Cadby T: Lumbar stabilization: core concepts and current literature, Part 1. Am J Phys Med Rehabil, 2005, 84: 473-480. [Medline] [CrossRef]

34) Lim HS, Roh SY, Lee SM: The relationship between pelvic tilt angle and disability associated with low back pain. J Phys Ther Sci, 2013, 25: 65-68. [CrossRef]

35) Yoo WG: Effect of the individual strengthening exercises for posterior pelvic tilt muscles on back pain, pelvic angle, and lumbar ROM of a LBP patient with excessive lordosis: a case study. J Phys Ther Sci, 2014, 26: 319-320. [Medline] [CrossRef]

36) Yoo WG: Effects of a self-assessment device for pelvic position on chronic back pain and range of motion of the trunk. J Phys Ther Sci, 2015, 27: 3939-3940. [Medline] [CrossRef]

37) Yu JS, An DH: Differences in lumbar and pelvic angles and gluteal pressure in different sitting postures. J Phys Ther Sci, 2015, 27: 1333-1335. [Medline] [CrossRef]

38) Hicks GE, Fritz JM, Delitto A, et al.: Preliminary development of a clinical prediction rule for determining which patients with low back pain will respond to a stabilization exercise program. Arch Phys Med Rehabil, 2005, 86: 1753-1762. [Medline] [CrossRef]

39) O'Sullivan PB, Burnett A, Floyd AN, et al.: Lumbar repositioning deficit in a specific low back pain population. Spine, 2003, 28: 1074-1079. [Medline] [CrossRef]

40) Oh BH, Kim HH, Kim CY, et al.: Comparison of physical function according to the lumbar movement method of stabilizing a patient with chronic low back pain. J Phys Ther Sci, 2015, 27: 3655-3658. [Medline] [CrossRef]

41) Fenety A, Walker JM: Short-term effects of workstation exercises on musculoskeletal discomfort and postural changes in seated video display unit workers. Phys Ther, 2002, 82: 578-589. [Medline]

42) Liao MH, Drury CG: Posture, discomfort and performance in a VDT task. Ergonomics, 2000, 43: 345-359. [Medline] [CrossRef]

43) Søndergaard KH, Olesen CG, Søndergaard EK, et al.: The variability and complexity of sitting postural control are associated with discomfort. J Biomech, 2010, 43: 1997-2001. [Medline] [CrossRef]

44) Takanishi T, Ebara T, Murasaki GI, et al.: Interactive model of subsidiary behaviors, work performance and autonomic nerve activity during visual display terminal work. J Occup Health, 2010, 52: 39-47. [Medline] [CrossRef]

45) Vergara M, Page A: Relationship between comfort and back posture and mobility in sitting-posture. Appl Ergon, 2002, 33: 1-8. [Medline] [CrossRef] 